\title{
PENERAPAN MODEL PEMBELAJARAN CORE (CONNECTING, ORGANIZING, REFLECTING, EXTENDING, DAN ORGANIZING) OLEH GURU DALAM PEMBELAJARAN MENULIS TEKS DESKRIPTIF KELAS VII SMP NEGERI 2 PERCUT SEI TUAN TAHUN PEMBELAJARAN 2018/2019
}

\author{
Oleh \\ Patimah (patimah2396@gmail.com) \\ Azhar Umar (azhar_umar60@yahoo.com) \\ Universitas Negeri Medan
}

\begin{abstract}
Abstrak
Penelitian ini merupakan penelitian deskriptif yang bertujuan untuk mengetahui sekaligus mendeskripsikan penerapan model pembelajaran CORE (connecting, organizing, reflecting, dan extending) oleh guru dalam pembelajaran menulis teks deskriptif kelas VII SMP Negeri 2 Percut Sei Tuan. Subjek penelitian ini adalah satu orang guru bahasa Indonesia kelas VII SMP Negeri 2 Percut Sei Tuan dan dan siswa kelas VII-6 berjumlah 27 orang. Metode yang digunakan dalam penelitian ini adalah metode Deskriptif. Instrumen yang digunakan adalah peneliti sendiri. Teknik pengumpulan data dilakukan dengan cara observasi partisipasi pasif (nonpartisipan) karena peneliti memang hadir di tempat kegiatan penelitian atau orang yang diamati, tetapi peneliti tidak terlibat aktif dalam kegiatan tersebut. Di lihat dari pelaksanaan model pembelajaran Core selama proses pembelajaran, diperoleh hasil penelitian menunjukkan bahwa penerapan model pembelajaran CORE (connecting, organizing, reflecting, dan extending) yang dilaksanakan guru dalam pembelajaran menulis teks deskriptif di kelas VII SMP Negeri 2 Percut Sei Tuan mendapat nilai 75 dan guru termasuk ke dalam kategori baik dalam menerapkan model pembelajaran di sekolah.
\end{abstract}

Kata kunci: Model Core, Pembelajaran, Menulis Teks Deskriptif.

\section{PENDAHULUAN}

Pembelajaran pada kurikulum 2013, guru dalam proses pembelajaran dituntut agar mampu menerapkan/menggunakan model pembelajaran yang inovatif dan model pembelajaran inovatif tersebut harus sesuai dengan pendekatan saintifik. Pelaksanan pembelajaran 
bukan hanya sekedar menjadikan model yang telah dipilih sebagai pajangan tetapi guru juga harus mampu menerapkan langkahlangkah model pembelajaran sesuai dengan sintak/langkah-langkah pelaksanaannya.

Model pembelajaran CORE adalah salah satu model pembelajaran inovatif yang sesuai dengan pendekatan saintifik. Menurut Nugroho (2016:17) model pembelajaran CORE sesuai dengan ciri-ciri pembelajaran berbasis kurikulum 2013 dan pendekatan santifik. Dalam bukunya diterangkan bahwa siswa adalah subjek yang memiliki kemampuan untuk secara aktif mencari, mengolah, mengontruksi, dan menggunakan pengetahuan sehingga pembelajaran harus memberikan kesempatan kepada siswa untuk mengontruksi pengetahuan dalam proses kognitifnya. Selain itu model pembelajaran CORE sama dengan PBL yaitu sama-sama lebih mengacu pada aliran pendidikan kontruktivmisme, dimana belajar berdasarkan pengalaman atau pengetahuan yang dimiliki.
Sejalan dengan pendapat beberapa para ahli di atas Calfee dkk (2010:133), mengungkapkan bahwa model CORE adalah model pembelajaran menggunakan metode diskusi yang dapat mempengaruhi perkembangan pengetahuan dan berpikir reflektif dengan melibatkan siswa. Model ini dijalankan dengan komponen utama mengarahkan siswa untuk mengoneksikan dan menghubungkan antara ingatan yang telah lalu dengan materi yang akan dipelajari selanjutnya. Siswa diwajibkan untuk aktif atau bekerja sendiri menemukan potonganpotongan pengetahuan yang dimiliki pada pembelajaran sebelumnya untuk membantu menyelesaikan masalah yang ada. Selain itu model pembelajaran CORE menuntut guru untuk terus mengawasi siswa saat berdiskusi dan mengarahkan siswa untuk memeriksa kembali hasil kerja dan memperbaikinya sebelum di kumpulkan kepada guru. Kegiatan ini akan menyadarkan siswa mengenai kesalahan yang tidak disadari saat mengerjakan tugas dan menghasilkan tugas akhir yang lebih baik dari sebelumnya. 
Shoimin

(2014:39)

mengungkapkan model pembelajaran CORE terbagi menjadi empat. Keempat aspek tersebut adalah sebagai berikut: 1) Connecting merupakan kegiatan mengoneksikan informasi lama dan informasi baru dan antarkonsep. 2) Organizing merupakan kegiatan mengorganisasikan ide-ide untuk memahami materi. 3) Reflecting merupakan kegiatan memikirkan kembali, mendalami, dan menggali informasi yang sudah didapat. 4)

Extending merupakan kegiatan untuk mengembangkan, memperluas, menggunakan, dan menemukan.

Berdasarkan empat fase model pembelajaran CORE tersebut terdapat 10 langkah-langkah yang harus di laksanakan guru, diantaranya: 1. Guru mengarahkan siswa membentuk kelompok kecil, 2. Guru menampilkan media pembelajaran yang efektif, dan mengarahkan siswa untuk mengamati, 3. Guru mengarahkan siswa untuk mengingat materi pada pertemuan sebelumnya, 4. Guru mengintruksikan siswa untuk membaca refrensi, 5. Guru mengintruksikan dan mengarahkan siswa membuat peta konsep dari gambar yang telah diamati, 6. Guru mengintruksikan siswa berdiskusi kelompok dalam menyelesaikan masalah yang diberikan, 7. Guru memberi kesem-patan kembali kepada siswa untuk mengoreksi hasil kerja sebelum di kumpulkan, 8. Guru memberikan kesempatan kepada siswa untuk mengomunikasikan hasil kerjanya, 9. Guru memberikan tugas individu kepada siswa, 10. Guru membimbing jalan diskusi dan mengarahkan siswa untuk mengumpulkan hasil kerjanya

Berdasarkan uraian tersebut, maka peneliti melakukan penelitian yang berjudul "Penerapan Model Pembelajaran CORE (Connecting, Organizing, Reflecting, Extending, dan Organizing) oleh Guru dalam Pembelajaran Menulis Teks Deskriptif Kelas VII SMP Negeri 2 Percut Sei Tuan Tahun Pembelajaran 2018/2019".

\section{METODE}

Pada penelitian ini metode yang digunakan oleh peneliti adalah metode Deskriptif. Penelitian ini berusaha untuk melaporkan keadaan objek yang diteliti sesuai dengan 
apa adanya yaitu untuk mengetahui

dan mendeskripsikan penerapan model pembelajaran CORE (connecting, organizing, reflecting, dan extending) oleh guru dalam pembelajaran menulis teks deskriptif kelas VII SMP Negeri 2 Percut Sei Tuan. Subjek penelitian ini adalah satu orang guru bahasa Indonesia kelas VII SMP Negeri 2 Percut Sei Tuan dan dan siswa kelas VII-6 berjumlah 27 orang. Instrumen yang digunakan adalah peneliti sendiri. Teknik pengumpulan data dilakukan dengan cara observasi partisipasi pasif (nonpartisipan) karena peneliti memang hadir di tempat kegiatan penelitian atau orang yang diamati, tetapi peneliti tidak terlibat aktif dalam kegiatan tersebut. Terdapat beberapa langkah yang akan dilakukan peneliti untuk mengumpulkan data antara lain observasi dan dokumentasi yaitu dengan merekam pelaksanaan pembelajaran guru selama kegiatan belajar mengajar berlangsung.

Analisis data dalam kegiatan penelitian ini dilakukan dengan teknik analisis data deskriptif, yaitu peneliti memaparkan data dan hasil analisis data dalam bentuk kalimat dengan langkah-langkah: 1) Menganalisis penerapan model CORE yang telah dilakukan guru, 2) Menjumlahkan nilai yang diperoleh dari penerapan model pembelajaran CORE yang dilakukan guru. 3) Menyimpulkan penerapan model CORE yang telah dilakukan guru dalam pembelajaran menulis teks deskripsi dan melakukan uji kategori untuk mengetahui kategori kemampuan guru dalam menerapkan model pembelajaran CORE.

\section{HASIL PENELITIAN DAN \\ PEMBAHASAN}

\section{Tabel 1}

Penilaian Hasil Observasi

Penerapan Model

pembelajaran CORE oleh Guru

dalam Pembelajaran Teks

Deskriptif

Nama Guru $\quad$ : $\quad$ Maya

Rospita, S.Pd

NIP

197007171995122006

Nama Sekolah : : SMP Negeri

2 Percut Sei Tuan

Mata Pelajaran : $\quad$ Bahasa Indonesia 


\begin{tabular}{|c|c|c|c|c|}
\hline No & Langkah-langkah & Indikator & Rubrik Penilain & $\begin{array}{c}\text { Skor } \\
\text { Penilaian }\end{array}$ \\
\hline \multirow[t]{7}{*}{1} & \multirow{6}{*}{$\begin{array}{l}\text { Connecting, meru- } \\
\text { Pakan kegiatan me- } \\
\text { ngoneksikan infor- } \\
\text { masi lama dan } \\
\text { informasi baru dan } \\
\text { antarkonsep. }\end{array}$} & \multirow{3}{*}{$\begin{array}{l}\text { 1. Guru mengarahkan } \\
\text { siswa membentuk } \\
\text { kelompok kecil }\end{array}$} & $\begin{array}{l}\text { Jika guru membentuk } \\
\text { kelompok kecil. }\end{array}$ & \\
\hline & & & $\begin{array}{l}\text { Jika guru membentuk } \\
\text { kelompok tetapi tidak } \\
\text { kelompok kecil }\end{array}$ & \\
\hline & & & $\begin{array}{l}\text { Jika guru tidak } \\
\text { membentuk kelompok. }\end{array}$ & 0 \\
\hline & & \multirow[t]{3}{*}{$\begin{array}{l}\text { 2. Guru menampilkan } \\
\text { media pembelajaran } \\
\text { yang efektif, dan } \\
\text { mengarahkan siswa } \\
\text { untuk mengamati. }\end{array}$} & $\begin{array}{l}\text { Jika guru menampilkan } \\
\text { media pembelajaran } \\
\text { berupa gambar-gambar } \\
\text { yang dapat di lihat oleh } \\
\text { semua siswa dan } \\
\text { mengarahkan siswa } \\
\text { untuk mengamati }\end{array}$ & 10 \\
\hline & & & $\begin{array}{l}\text { Jika guru menampilkan } \\
\text { media pembelajaran } \\
\text { yang dapat di lihat oleh } \\
\text { seluruh siswa tetapi guru } \\
\text { tidak mengarahkan siswa } \\
\text { untuk mengamati media. }\end{array}$ & \\
\hline & & & $\begin{array}{lr}\text { Jika guru } & \text { tidak } \\
\text { menampilkan } & \text { media } \\
\text { pembelajaran dan } & \text { tidak } \\
\text { mengarahkan siswa } & \text { suk menyelesaikan } \\
\text { untuk } & \\
\text { tugas }\end{array}$ & \\
\hline & & $\begin{array}{l}\text { 3. Guru mengarahkan } \\
\text { siswa untuk mengingat } \\
\text { materi pada pertemuan }\end{array}$ & $\begin{array}{l}\text { Jika guru mengarakan } \\
\text { siswa untuk mengingat } \\
\text { materi yang telah lalu }\end{array}$ & 10 \\
\hline
\end{tabular}




\begin{tabular}{|c|c|c|c|c|}
\hline & & sebelumnya & $\begin{array}{l}\text { mengenai struktur dan } \\
\text { ciri-ciri menulis teks } \\
\text { deskripsi }\end{array}$ & \\
\hline & & & $\begin{array}{lr}\text { Jika guru langsung } \\
\text { memberitahu } & \text { dan } \\
\text { menjelaskan } & \text { materi } \\
\text { struktur teks } & \text { deskripsi } \\
\text { dan penulisan } & \text { teks } \\
\text { deskripsi }\end{array}$ & \\
\hline & & & $\begin{array}{l}\text { Jika guru tidak } \\
\text { mengarahkan dan } \\
\text { menjelaskan kepada } \\
\text { siswa untuk mengingat } \\
\text { pelajaran yang telah lalu } \\
\text { yang berkaitan dengan } \\
\text { penulisan teks deskripsi }\end{array}$ & \\
\hline & & Skor Connectin & & 20 \\
\hline 2 & $\begin{array}{l}\text { Pengorgansasian } \\
\text { ide-ide untuk } \\
\text { memahami } \\
\text { materi yang } \\
\text { dilakukan oleh } \\
\text { siswa dengan } \\
\text { bimbingan guru } \\
\text { (organizing [O]). }\end{array}$ & $\begin{array}{l}\text { 4. Guru mengintruksikan } \\
\text { siswa untuk membaca } \\
\text { refrensi }\end{array}$ & $\begin{array}{l}\text { Jika guru mengin- } \\
\text { truksikan kepada siswa } \\
\text { untuk mencari dan } \\
\text { mengumpulkan infor- } \\
\text { masi lebih dalam tentang } \\
\text { menulis teks deskriptif } \\
\text { dari membaca buku, dan } \\
\text { menjelaskan hal-hal } \\
\text { yang sulit untuk } \\
\text { dipahami siswa. }\end{array}$ & 10 \\
\hline & & & $\begin{array}{l}\text { Jika guru hanya } \\
\text { mengintruksikan siswa } \\
\text { untuk mencari informasi } \\
\text { dari buku tetapi tidak } \\
\text { menjelaskan hal-hal }\end{array}$ & \\
\hline
\end{tabular}




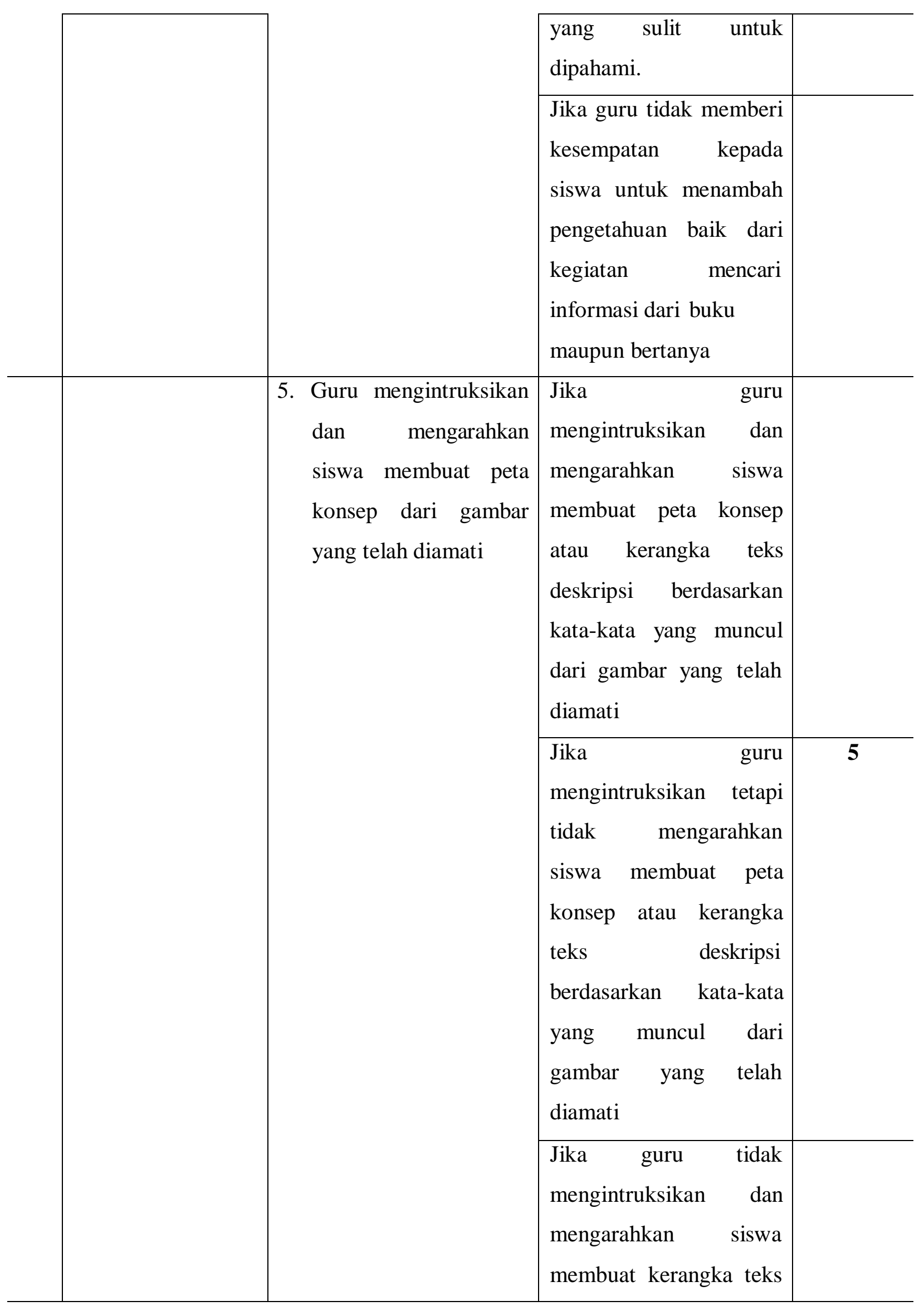




\begin{tabular}{|c|c|c|c|c|}
\hline & & & deskripsi. & \\
\hline & & $\begin{array}{l}\text { 6. Guru mengintruksikan } \\
\text { siswa berdiskusi } \\
\text { kelompok, memecahk- } \\
\text { an masalah berdasark- } \\
\text { an pengalaman belajar. }\end{array}$ & $\begin{array}{lr}\text { Jika guru } & \text { memberi } \\
\text { tugas, mengintruksikan } \\
\text { siswa } & \text { berdiskusi } \\
\text { kelompok } & \text { dan } \\
\text { mengawasi } & \text { kegiatan } \\
\text { siswa dalam } & \text { setiap } \\
\text { kelompok } & \end{array}$ & 10 \\
\hline & & & $\begin{array}{l}\text { Jika guru memberi tugas } \\
\text { dan mengintruksikan } \\
\text { siswa berdiskusi } \\
\text { kelompok tetapi tidak } \\
\text { mengawasi kegiatan } \\
\text { siswa dalam setiap } \\
\text { kelompok }\end{array}$ & \\
\hline & & & $\begin{array}{l}\text { Jika guru tidak member } \\
\text { tugas kelompok }\end{array}$ & \\
\hline & & skor organizing & & 25 \\
\hline 3 & $\begin{array}{l}\text { Memikirkan } \\
\text { kembali, } \\
\text { mendalami, dan } \\
\text { menggali } \\
\text { informasi, yang } \\
\text { sudah didapat } \\
\text { dan dilaksanakan } \\
\text { dalam kegiatan }\end{array}$ & $\begin{array}{l}\text { 7. Guru memberi kesem- } \\
\text { patan kembali kepada } \\
\text { siswa untuk } \\
\text { mengoreksi hasil kerja } \\
\text { sebelum di } \\
\text { kumpulkan. }\end{array}$ & $\begin{array}{l}\text { Jika guru memberikan } \\
\text { kesempatan kepada } \\
\text { siswa untuk memper- } \\
\text { baiki hasil kerjanya, } \\
\text { menanyakan hal-hal } \\
\text { yang tidak dimengerti } \\
\text { dan membantu untuk } \\
\text { memperbaiki. }\end{array}$ & 10 \\
\hline & $\begin{array}{l}\text { belajar kelompok } \\
\text { siswa (reflecting } \\
{[\mathrm{R}] \text { ) }}\end{array}$ & & $\begin{array}{l}\text { Jika guru memberikan } \\
\text { kesempatan kepada } \\
\text { siswa untuk memper- } \\
\text { baiki hasil kerjanya, } \\
\text { namun tidak membantu } \\
\text { menyelesaikan kesulitan }\end{array}$ & \\
\hline
\end{tabular}




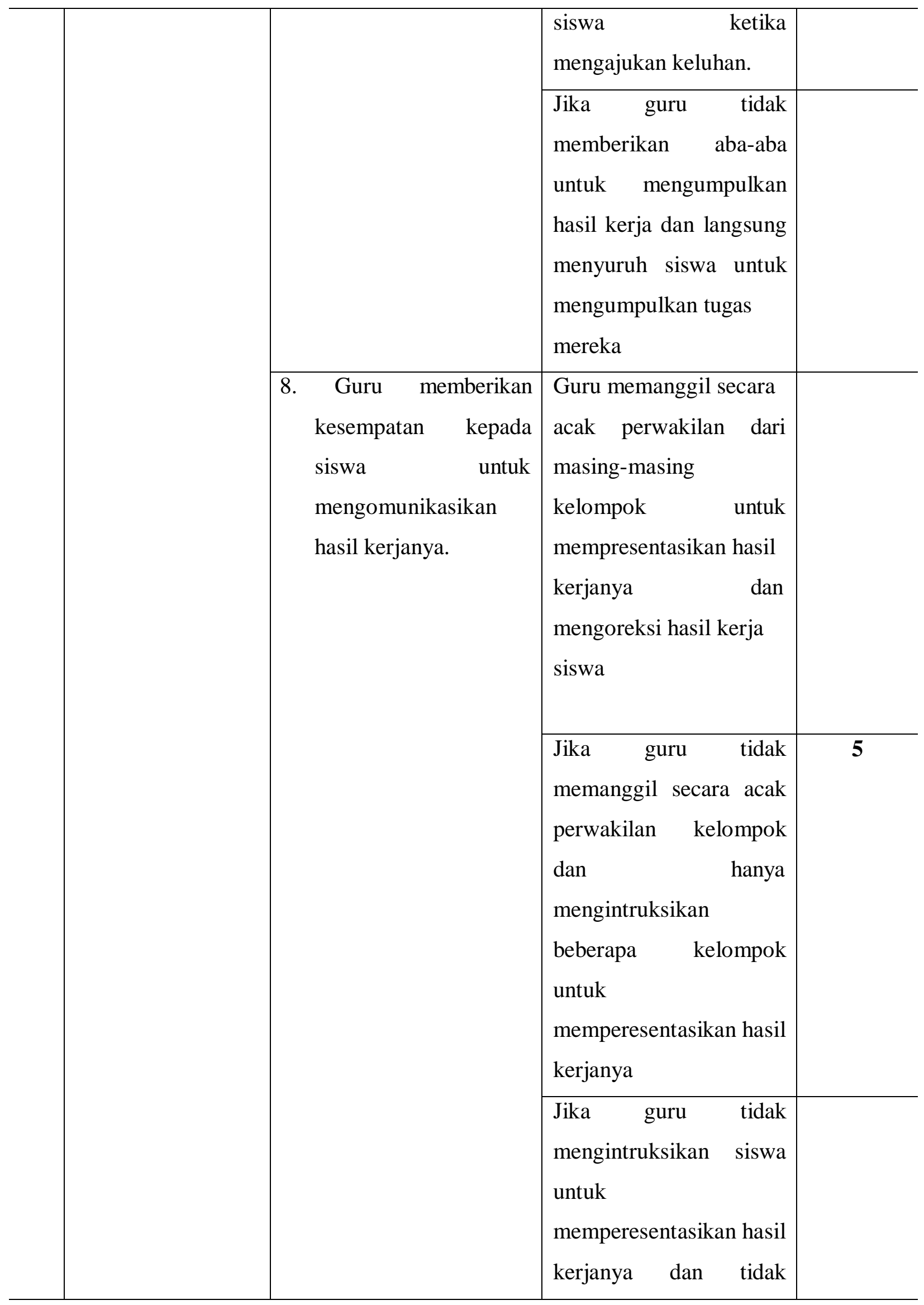




\begin{tabular}{|c|c|c|c|c|}
\hline & & & $\begin{array}{l}\text { mengoreksi hasil kerja } \\
\text { siswa }\end{array}$ & \\
\hline \multicolumn{4}{|c|}{ Skor reflecting } & 15 \\
\hline \multirow[t]{6}{*}{4} & \multirow{6}{*}{$\begin{array}{l}\text { Pengembangan, } \\
\text { memperluas, } \\
\text { menggunakan, } \\
\text { dan menemukan, } \\
\text { melalui tugas } \\
\text { individu dengan } \\
\text { mengerjakan } \\
\text { tugas (extending } \\
{[\text { E]). }}\end{array}$} & \multirow[t]{3}{*}{$\begin{array}{l}\text { 9. Guru memberikan } \\
\text { tugas individu kepada } \\
\text { siswa }\end{array}$} & $\begin{array}{l}\text { Jika guru memberikan } \\
\text { tugas lanjutan secara } \\
\text { individu kepada seluruh } \\
\text { siswa }\end{array}$ & 10 \\
\hline & & & $\begin{array}{l}\text { Jika guru memberikan } \\
\text { tugas tetapi tidak } \\
\text { individu }\end{array}$ & \\
\hline & & & $\begin{array}{l}\text { Jika guru tidak } \\
\text { memberikan tugas lanjut } \\
\text { kepada siswa. }\end{array}$ & \\
\hline & & \multirow[t]{3}{*}{$\begin{array}{l}10 \text { Guru membimbing } \\
\text { jalan diskusi dan } \\
\text { mengarahkan siswa } \\
\text { untuk mengumpulkan } \\
\text { hasil kerjanya. }\end{array}$} & $\begin{array}{l}\text { Guru membimbing jalan } \\
\text { diskusi dan } \\
\text { mengarahkan siswa } \\
\text { untuk mengumpulkan } \\
\text { hasil kerjanya }\end{array}$ & \\
\hline & & & $\begin{array}{l}\text { Guru membimbing jalan } \\
\text { diskusi tetapi tidak } \\
\text { mengarahkan siswa } \\
\text { untuk mengumpulkan } \\
\text { hasil kerjanya }\end{array}$ & 5 \\
\hline & & & $\begin{array}{l}\text { Guru tidak membimbing } \\
\text { jalan diskusi dan tidak } \\
\text { mengarahkan siswa } \\
\text { untuk mengumpulkan } \\
\text { hasil kerjanya. }\end{array}$ & \\
\hline \multicolumn{4}{|c|}{ Skor extending } & 15 \\
\hline \multicolumn{4}{|c|}{ Jumlah } & 75 \\
\hline
\end{tabular}


Tabel ini menjelaskan tentang pelaksanaan pembelajaran guru selama kegiatan belajar mengajar berlangsung. Berdasarkan tabel hasil penelitian, dalam 10 langkah pada 4 tahapan model pembelajaran CORE yang dilaksanakan guru dalam pembelajaran menulis teks deskripsi di kelas VII-6 SMP Negeri 2 Percut Sei Tuan tahun pembelajaran 2018/2019 memperoleh jumlah 75 .

Adapun kegiatan pelaksanaan pembelajaran guru dapat dijelaskan sebagai berikut:

a) Kegiatan mengoneksikan informasi lama dan informasi baru dan antarkonsep.

Dari tiga kegiatan connecting yang harus dilakukan, guru hanya melakukan dua kegiatan yaitu: Guru menampilkan media pembelajaran berupa gambargambar pemandangan Danau Toba di papan tulis dan mengarahkan siswa untuk mengamati gambar-gambar tersebut. Media pembelajaran yang di tampilkan guru sudah termasuk efektif sebab selain guru menampilkan media di papan tulis guru juga membagikan media yang sama kepada setiap kelompok dalam bentuk gambar yang diperkecil dan hal ini tentu akan mempermudah siswa saat mengamati gambar. Setelah siswa mengamati gambar guru mengarahkan siswa untuk mengingat materi pada pertemuan sebelumnya mengenai struktur teks deskripsi dan bahasa yang digunakan dalam teks deskripsi dan masing-masing dari perwakilan kelompok menyampaikan pendapatnya.

b) Pengorgansasian ide-ide untuk memahami materi yang dilakukan oleh siswa dengan bimbingan guru (organizing [O]). Dari tiga kegiatan organizing yang harus dilakukan, guru hanya melakukan dua kegiatan yaitu: Guru mengarahkan siswa untuk melihat buku siswa dan membaca langkah-langkah menulis teks deskripsi. Setelah siswa selesai membacakan cara menulis teks deskripsi, guru mengarahkan siswa untuk menyampaikan kembali hal-hal yang sudah dipelajari dan dikaitkan dengan 
materi menulis teks deskripsi agar siswa lebih mudah dalam memahami. Kekurangan guru pada tahap ini adalah guru mengintruksikan siswa untuk membuat konsep atau kerangka teks deskripsi berdasarkan katakata yang telah muncul dari hasil mengamati, namun tidak membimbing ataupun memberi contoh bagaimana cara membuat peta konsep dan mengembangkan konsep tersebut menjadi sebuah tulisan teks deskripsi. Sehingga pada kegiatan organizing guru memperoleh nilai 25 .

c) Memikirkan kembali, mendalami, dan menggali informasi, yang sudah didapat dan dilaksanakan dalam kegiatan belajar kelompok siswa (reflecting [R])

Kegiatan reflecting diterapkan guru dengan cara memberikan kesempatan kepada siswa untuk memperbaiki hasil kerjanya, mengawasi, mendatangi setiap kelompok dan mengingatkan penulisan harus memuat ketiga struktur teks deskripsi. Setelah waktu yang diberikan habis untuk berdiskusi menulis teks deskripsi, guru mengarahkan siswa untuk mempresentasikan hasil kerja mereka. Kekurangan pada kegiatan reflecting adalah guru tidak memanggil secara acak perwakilan dari masingmasing kelompok untuk membacakan hasil kerjanya sehingga yang membaca ke depan akan tetap hanya untuk orang yang memiliki kepercayaan diri saja. Dari kegiatan reflecting yang diterapkan guru maka guru mendapatkan nilai 15 sebab dari dua langkah-langkah reflecting ada satu langkah-langkah yang pointnya dikurang 5 .

d) Pengembangan, memperluas, menggunakan, dan menemukan, melalui tugas individu dengan mengerjakan tugas (extending [E]).

Kegiatan extending pada pelaksanaan pembelajaran dilakukan guru dengan cara memberikan tugas lanjutan secara individu kepada seluruh siswa tentang menulis teks deskripsi berdasarkan lingkungan 
sekolah tetapi karena waktu tidak memungkinkan untuk mengamati dan mengontrol secara langsung kegiatan siswa dalam menyelesaikan tugas mandiri sehingga guru mengintruksikan siswa untuk mengerjakannya di rumah

\section{SIMPULAN DAN SARAN}

\begin{tabular}{lrr}
\multicolumn{2}{c}{ Berdasarkan } & Berdasarkan \\
hasil penelitian dan & pembahasan \\
mengenai penerapan & model \\
pembelajaran & CORE & (connecting, \\
organizing, reflecting, & dan \\
extending) oleh guru & dalam \\
Pembelajaran & Menulis & Teks \\
Deskriptif kelas VII SMP Negeri 2
\end{tabular}
Percut Sei Tuan tahun Ajaran 2018/2019, maka dapat disimpulkan, guru telah melaksanakan 10 langkah pembelajaran yang terbagi ke dalam 4 fase sesuai dengan sintak model CORE. Penerapan model pembelajaran CORE (connecting, organizing, reflecting, dan extending) yang dilaksanakan guru dalam pembelajaran teks deskriptif di kelas VII tergolong baik dan berhasil jika dilihat dari pemenuhan kriteria keterlaksanaan langkah pembelajaran dan juga skor yang dihasilkan saat pelaksanaan penelitian yaitu sebesar 75. Dari hasil pembahsan ada tiga indikator yang tidak di terapkan dengan baik dan benar sesuai dengan rubik penilaian.

Adapun beberapa saran yang hendak disampaikan peneliti adalah sebagai berikut: (1) Diharapkan kepada guru untuk dapat lebih meningkatkan diri dalam melaksanakan pembelajaran sesuai dengan langkah-langkah model pembelajaran yang ditentukan sehingga kegiatan pembelajaran menjadi lebih efektif dan mencapai kepada tujuan pembelajaran yang lebih baik lagi. (2) Diharapkan kepada pihak sekolah agar lebih memperhatikan pelaksanaan pembelajaran guru agar kegiatan pembelajaran yang dilaksanakan guru kedepannya dapat terlaksana lebih baik lagi.

\section{DAFTAR PUSTAKA}

Arikunto, Suharsimi. 2009.

Manajemen

Penelitian.

Jakarta: PT. RINEKA CIPTA.

Calfee, Robert C, dkk. 2010. Increasing Teachers' 
Metacognition Develops

Students' Higher Learning during Content Area Literacy Instruction: Findings from the Read-Write Cycle Project. Issues in Teacher Education. 19(2) 127-146.

Nugroho, Danis Agung. 2016. Perangkat Pembelajaran Geometri SMA dengan Mengadaptasi Model CORE. Yogyakarta: universitas Negeri Yogyakarta.

Shoimin, Aris. 2014. 68 Model Pembelajaran Inovatif dalam Kurikulum 2013. Yogyakarta: Ar-Ruzz Media

Sugiyono. 2014. Metode Penelitian

Pendidikan (Pendekatan

Kuantitatif, Kualitatif, dan

$R \& D)$. Bandung: ALFABETA. 